\title{
Analysis of Temperature Distribution And Performance of Motorcycle Engine Fins
}

\author{
Ahmad Faizal $^{1}$, Slamet Wahyudi ${ }^{2}$, Femiana Gapsari ${ }^{3}$ \\ ${ }^{1}$ University of Brawijaya, Indonesia, ahmatfaizal@ymail.com \\ ${ }^{2}$ University of Brawijaya, Indonesia, slamet_w72@ub.ac.id \\ ${ }^{3}$ University of Brawijaya, Indonesia, memi_kencrut@ub.ac.id
}

\begin{abstract}
Air-cooled motorcycle engines release heat into the atmosphere through the process of forced convection, an important component for increasing the convection heat coefficient and the rate of heat transfer is fins. The rate of heat transfer depends on the geometry of the fin, the surface of the fin, the thickness of the fin, the distance between the fins, the temperature of the environment, and the air velocity. The research was conducted by varying the air velocity with the addition of holes in the geometry of convex fins. The main purpose of this study was to analyze the rate of heat transfer that occurs in the geometry of perforated fins by varying the air velocity. Physical models are designed using the Autodesk Inventor Professional 2020 application and simulated by Dynamics 2019 Autodesk Computational Fluid. The result of $4 \mathrm{~mm}$ perforated convex geometry analysis is better than $2 \mathrm{~mm}$ and $6 \mathrm{~mm}$ perforated fins and non-perforated. Due to this, the rate of heat transfer has increased so that the coefficient of convection heat transfer increases and the decrease in the temperature of perforated fins is consistently higher than non-perforated fins, improving the efficiency and effectiveness of motorcycle fins so that the performance of motorcycle engines also increases indicated by the temperature distribution.
\end{abstract}

Key words: Air velocity, Heat transfer, Motorcycle fins, CFD.

\section{INTRODUCTION}

Transportation is increasing as the population grows and people's needs for transportation are fast and easy. One of the means of transportation that can help is motor vehicles [1]. Motor vehicles with internal combustion engines to generate energy perform the combustion process. The combustion process was continuous in the engine resulting in overheating. This requires a detailed study to cool the machine at an ideal working temperature with a cooling system. Fins are an important component for increasing the coefficient of convection heat and the rate at which heat transfer releases heat into the atmosphere through forced convection. The rate of heat transfer depends on wind speed, geometry, surface area, and ambient temperature. The main objective in this study was to increase the rate of heat transfer geometry of convex shape fins adding holes $2 \mathrm{~mm}, 4 \mathrm{~mm}$, $6 \mathrm{~mm}$, and varying wind speed to improve the performance of motorcycle fin engines carried out a computerized approach using Computational Fluid Dynamics (CFD) software.

There is a lot of literature that discusses heat transfer with forced convection mode on motorcycle fins. Based on research [2] conducted experimentally and simulated on a Honda $100 \mathrm{cc}$ Motorcycle to analyze thermal properties by varying the geometry, material, and thickness of cylinder fins. The geometric shapes of the fins are rectangular models created by varying geometric shapes such as circular and curved and the thickness of standard fins is $3 \mathrm{~mm}$, reduced the thickness of the fins to $2.5 \mathrm{~mm}$ on each geometric shape. The 204 alloy aluminum material that has $110-150 \mathrm{~W} / \mathrm{m} \bullet \mathrm{k}$ thermal conductivity in this test is varied with aluminum alloy 6061 and magnesium which has high thermal conductivity. For its simulation testing, pro/ENGINEER software is used on 3D modeling, and analysis is performed using ANSYS. By varying geometric shapes and reducing their thickness and varying materials, the fin's weight is reduced, improving its effectiveness and efficiency. The thermal analysis obtained in this study was better-curved fin shape than other geometric shapes and Aluminum Alloy 6061 material by reducing fin thickness by $2.5 \mathrm{~mm}$ better due to higher heat transfer rate.

By changing the thickness of the fin and changing the material of the fin geometry shape compared to the machine that has the thickness of the fin and its geometric shape it can increase the rate of heat transfer so that increasing the rate of heat dissipation on the fin will increase the efficiency of the machine. This study [3], was conducted in simulation on a $115 \mathrm{cc}$ Bajaj Caliber Motorcycle to analyze thermals by varying the material, slit size and length, and thickness of the fins. The materials used are Aluminum Alloy 204 which has a thermal conductivity of $120 \mathrm{~W} / \mathrm{m} \bullet \mathrm{k}$ varied with Aluminum 
Alloy 2014, Aluminum Alloy 6061, and Aluminum Alloy C443 which has a much higher thermal conductivity of $140-200 \mathrm{~W} / \mathrm{m} \bullet \mathrm{k}$. The geometric shape of the fin is rectangular with a thick curve of $3 \mathrm{~mm}$ reduced to $2.5 \mathrm{~mm}$ has a varied gap of $5 \mathrm{~mm}, 7.5 \mathrm{~mm}$, and $10 \mathrm{~mm}$ at the end of the fin. 3D modeling using SolidWorks software and analytics using ANSYS. The tests in this study were conducted with simulations that obtained results using rectangular geometric shapes, with the 2014 Aluminum Alloy material with a gap width of $7.5 \mathrm{~mm}$ having a high heat transfer rate followed by Aluminum Alloy 6061 and Aluminum Alloy C443 materials.

There are several factors that make the rate of heat transfer on the fin increase i.e. depending on the geometry of the fin, the surface area of the fin, the thickness of the fin, and the material.The research [4] was conducted experimentally and simulated by varying the material and thickness of the Linear Cylinder Engine aimed at improving heat transfer rate as well as its efficiency. Cylinder linear engines are analyzed using different materials such as Cast Iron, Magnesium Alloy, and Titanium Alloy with varying thicknesses of $0.5 \mathrm{~mm}, 1 \mathrm{~mm}$, and $1.5 \mathrm{~mm}$. 3D modeling and analysis using ANSYS software. The results showed that the Titanium Alloy material and $0.5 \mathrm{~mm}$ thickness obtained a good high temperature $\left(472.5^{\circ} \mathrm{C}\right)$ compared to other cylinder linear materials. Reducing its thickness increases the rate of heat transfer better. Linear cylinders with titanium alloy improve better temperature changes, thermal gradients, and thermal flux.

In the study [5]-[6] experiments and simulations were conducted that compared the air releasing heat into the atmosphere through forced convection mode by varying the geometric shapes of the fins, namely cylinders, concave and convex. The material used is Aluminum Alloy 6061 which has a thermal conductivity of $180 \mathrm{~W} / \mathrm{m} \bullet \mathrm{k}$ with a cylinder diameter of $28 \mathrm{~mm}$ and an overall length of $10 \mathrm{~mm}$. The temperature on the inside of the cylinder is set at $222^{\circ} \mathrm{C}$ during combustion and the convection heat transfer coefficient is $22 \mathrm{~W} / \mathrm{m} 2 \cdot \mathrm{K}$. Creation of $3 \mathrm{D}$ models using AUTODESK INVENTOR 2015 software for analysis using modern AUTODESK NASTRAN 2015 software. By changing the shape of the fin, the rate of heat transfer will increase, but the surface area of the fin also affects the decrease in the rate of heat transfer. In this study, the results obtained by convex geometric shapes were better than other geometries. This can happen because using convex fins can increase the rate of heat transfer with the same surface area. This research is continued from previous research [7], the addition of holes [8] of different diameters to analyze the heat transfer temperature distribution of forced convection modes and vary various airflow speeds [9] to obtain the right efficiency and effectiveness so that the performance of motorcycle engines is better analysis is carried out by simulation methods.

\section{MATERIAL \& METHODOLOGY}

The motorcycle fin engine consists of a 110cc Honda Absolute Revo engine block type. convex fin annular geometry perforated $2 \mathrm{~mm}, 4 \mathrm{~mm}$, and $6 \mathrm{~mm}$ with cylinder diameter in 50 $\mathrm{mm}$, outer diameter $55 \mathrm{~mm}$, fin diameter $65 \mathrm{~mm}$, fin length $100 \mathrm{~mm}$, the material used Aluminum 6061 has thermal conductivity $180 \mathrm{~W} / \mathrm{m} \bullet \mathrm{k}$, fin thickness $2.5 \mathrm{~mm}$, the gap between fins $7.5 \mathrm{~mm}$, fin puffy radius $2.5 \mathrm{~mm}$, inner cylinder wall temperature set at $150^{\circ} \mathrm{C}$ or $423 \mathrm{~K}$ during combustion as shown in Figure. 1. Physical model motorcycle fin made using Autodesk Inventor Professional 2021 software.

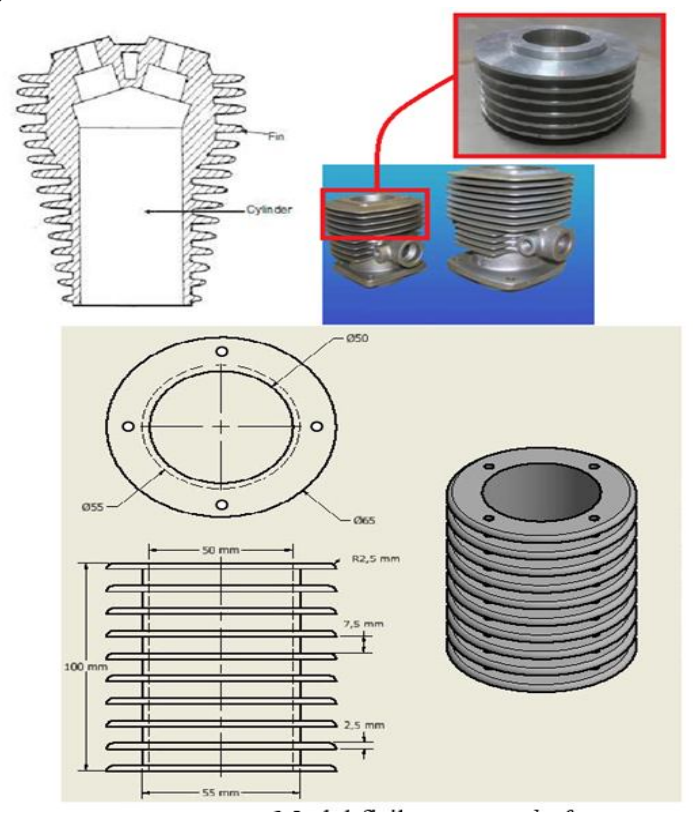

Figure 1: Physical model motorcycle fin

The physical model is transferred to the Dynamics Computational Fluids (CFD) application to become a compute domain, specifying material properties, boundary conditions, initial condition defining fluid properties representing real conditions or working conditions as below :

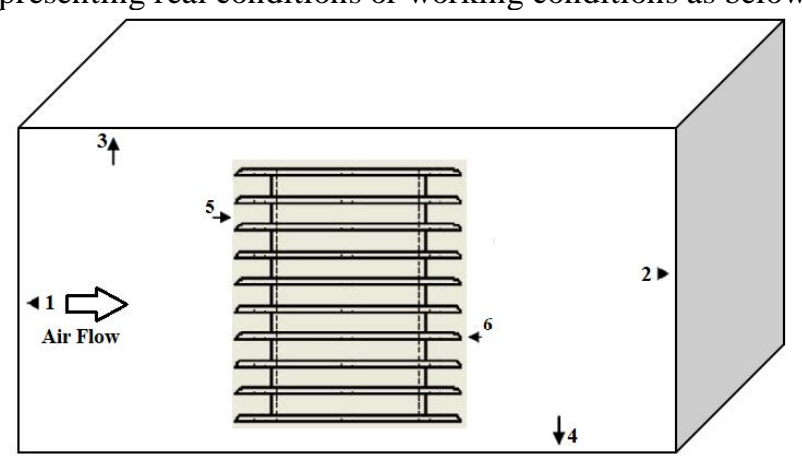

Figure 2: Wind tunnel boundary conditions

Figure 2. indicates the appropriate limit conditions [10] used to complete the heat flow through the cylinder. The limit conditions [11] applied to the expired domain help in maintaining continuity as follows :

(1) The entrance is given a vehicle speed variation of 60,80 , and $100 \mathrm{~km} / \mathrm{h}$. The speed and temperature of the incoming air are selected depending on the case being resolved. 
Ahmad Faizal et al., International Journal of Emerging Trends in Engineering Research, 9(4), April 2021, 361 - 366

(2) The exit is given a fixed pressure condition of $101,325 \mathrm{kPa}$ which is the pressure of 1 atmosphere.

(3) The upper part is given a temperature of $30^{\circ} \mathrm{C}$ or $303 \mathrm{~K}$ which is the ambient temperature.

(4) The lower part is given a temperature of $30^{\circ} \mathrm{C}$ or $303 \mathrm{~K}$ which is the ambient temperature.

(5) The inner cylinder wall is rated at $150^{\circ} \mathrm{C}$ or $423 \mathrm{~K}$ set during combustion.

(6) The fin part is defined as a solid area. To be further solved by the equation of heat transfer rate.

Table 1: Boundary condition

\begin{tabular}{|c|c|}
\hline Parameter & Unit \\
\hline Wind speed & $20,40,60,80,100(\mathrm{~km} / \mathrm{h})$ \\
\hline Ambient temperature & $30^{\circ} \mathrm{C}$ or $303 \mathrm{~K}$ \\
\hline Atmospheric pressure & $101.325(\mathrm{kPa})$ \\
\hline Current direction & Left to right \\
\hline $\begin{array}{c}\text { The temperature of wall in } \\
\text { the cylinder }\end{array}$ & $150^{\circ} \mathrm{C}$ or $423 \mathrm{~K}$ \\
\hline
\end{tabular}

\subsection{Metodologi CFD}

The Methodology of Computational Fluid Dynamics (CFD) in this research, as follows :

1.) Import motorcycle fin geometry into the Computational Fluid Dynamics (CFD) application.

2.) Develop fluid domains around cylinder geometry to capture flow physics.

3.) Create a mesh element and create a name selected for the relevant surface in geometry.

4.) Set model details.

5.) Select material, Aluminum, and air.

6.) Apply incoming wind speed, exit pressure, environmental temperature, and cylinder wall temperature as limit conditions.

7.) Initialization of meshing and solutions.

8.) Calculate solutions by gradually increasing the number of iterations while monitoring plot convergence.

\subsection{Governing Equations}

Solving in Computational Fluids Dynamics (CFD) using Finite Element Method (FEM) method and in this computationally based research using standard fluid flow equations from Navier-strokes [12] written mathematically as follows :

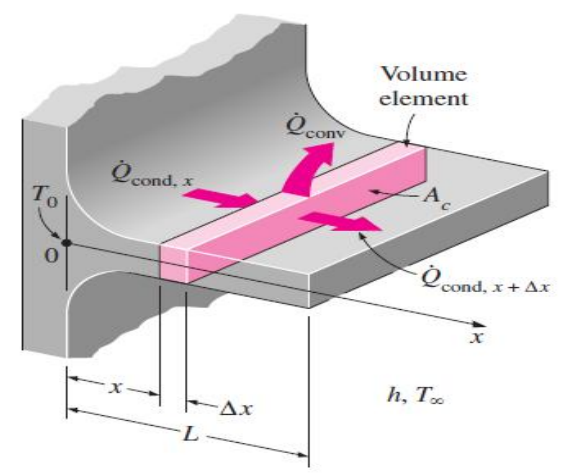

Figure 3: Geometry of border condition fins[13]
From the hot conduction law of The Fourier Law :

$$
q=-k(T) A_{c r} \frac{d T}{d x}
$$

Differential equations that regulate heat transfer in fins :

$$
\frac{d}{d x}\left[k(T) \frac{d T}{d x}\right]-\frac{h}{A_{c r}} P\left(T-T_{\infty}\right)+q_{\text {int. }}(T)=0
$$

The rate of heat transfer from the fin can also be determined taking into account the heat transfer of a differential element of the fin's volume and integrate it to the fin's cell, the approach of the boundary conditions used in this study is as follows :

$\frac{d}{d x}\left[k_{\infty}\left[1+\lambda\left(T-T_{\infty}\right)\right] \frac{d T}{d x}\right]-\frac{h P\left(T-T_{\infty}\right)}{A_{c}}+q_{\infty}\left[1+\psi\left(T-T_{\infty}\right)\right]=0$

Where the condition of the boundary of all fins can be determined from the Fourier Law, written as follows :

$$
\begin{aligned}
& X=0, \quad \theta=1 \\
& X=1, \quad \frac{d \theta}{d X}=0
\end{aligned}
$$

The governing equation involves the immortality of mass, momentum, and energy equations. For three-dimensional flows that line up with potential equations for finding pressure and speed at domain points, flows written in Cartesian coordinates, with $\mathrm{x}$ transverse to end, $\mathrm{y}$ in the vertical direction, and $\mathrm{z}$ towards fins and flows used in conjunction with continuity equations, equations used in Computational Fluids Dynamics (CFD) are written as follows :

Continuity equation for stable and uncommentable flow :

$$
\frac{\partial u}{\partial x}+\frac{\partial v}{\partial y}+\frac{\partial w}{\partial z}=0
$$

Momentum equation :

$u \frac{\partial u}{\partial x}+v \frac{\partial u}{\partial y}+w \frac{\partial u}{\partial z}=-\frac{1}{\rho} \frac{\partial p}{\partial x}+v\left(\frac{\partial^{2} u}{\partial x^{2}}+\frac{\partial^{2} u}{\partial y^{2}}+\frac{\partial^{2} u}{\partial z^{2}}\right)$

$u \frac{\partial v}{\partial x}+v \frac{\partial v}{\partial y}+w \frac{\partial v}{\partial z}=-\frac{1}{\rho} \frac{\partial p}{\partial y}+v\left(\frac{\partial^{2} v}{\partial x^{2}}+\frac{\partial^{2} v}{\partial y^{2}}+\frac{\partial^{2} v}{\partial z^{2}}\right)$

and

$u \frac{\partial w}{\partial x}+v \frac{\partial w}{\partial y}+w \frac{\partial w}{\partial z}=-\frac{1}{\rho} \frac{\partial p}{\partial z}+v\left(\frac{\partial^{2} w}{\partial x^{2}}+\frac{\partial^{2} w}{\partial y^{2}}+\frac{\partial^{2} w}{\partial z^{2}}\right)$

Energy equations :

$$
u \frac{\partial T}{\partial x}+v \frac{\partial T}{\partial y}+w \frac{\partial T}{\partial z}=\alpha\left(\frac{\partial^{2} T}{\partial x^{2}}+\frac{\partial^{2} T}{\partial y^{2}}+\frac{\partial^{2} T}{\partial z^{2}}\right)
$$

Lastly for turbulence obtained by using the equation of the model Spalart- Allmaras most appropriate for the heat flow of the outer cylinder, in this study the model equation is solved for the viscosity of turbulent kinematics[14]. 


\section{RESULT \& DISCUSSION}

The temperature distribution at $4 \mathrm{~mm}$ perforated motorcycle fins at speeds of 20,40,60,80, and $100 \mathrm{~km} / \mathrm{h}$ obtained under different conditions can be seen with the contours of temperature variations along the fin surface shown in the image below :

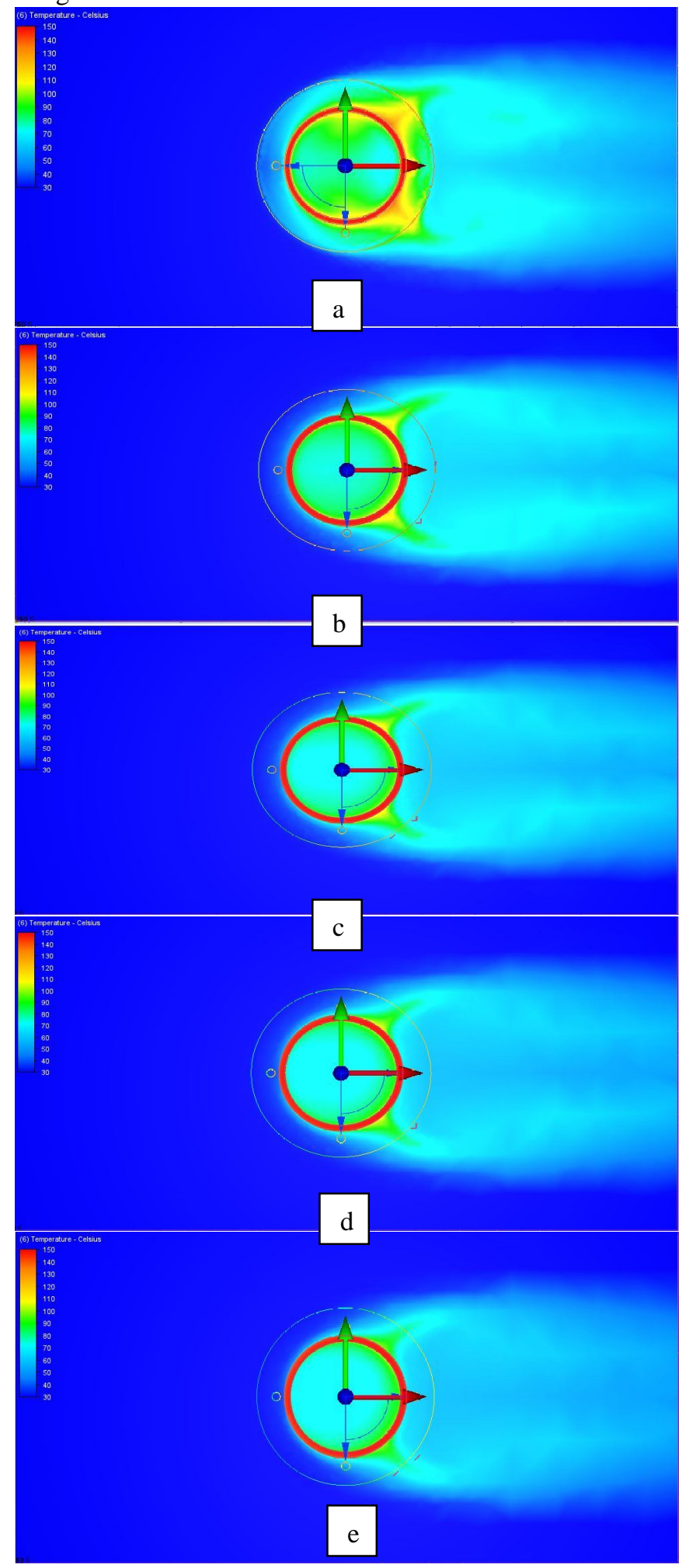

Figure 4: Speed temperature distribution (a) $20 \mathrm{~km} / \mathrm{h}$, (b) 40 $\mathrm{km} / \mathrm{h}$, (c) $60 \mathrm{~km} / \mathrm{h}$, (d) $80 \mathrm{~km} / \mathrm{h}$ and (e) $100 \mathrm{~km} / \mathrm{h}$
Figure 4 shows from the Temperature distribution Image displays different temperature contours due to the wind speed varying from upstream to downstream, wind speed increases and passes through the surface of the fin perforated $4 \mathrm{~mm}$ with a wind speed of $100 \mathrm{~km} / \mathrm{h}$ the displacement rate is better compared to the variation of holes $2 \mathrm{~mm}$ and $6 \mathrm{~mm}$ because it brings heat out into the outside air more effectively at the same time there is a decrease in temperature in the motorcycle fin so that efficiency increases and engine performance also increases.

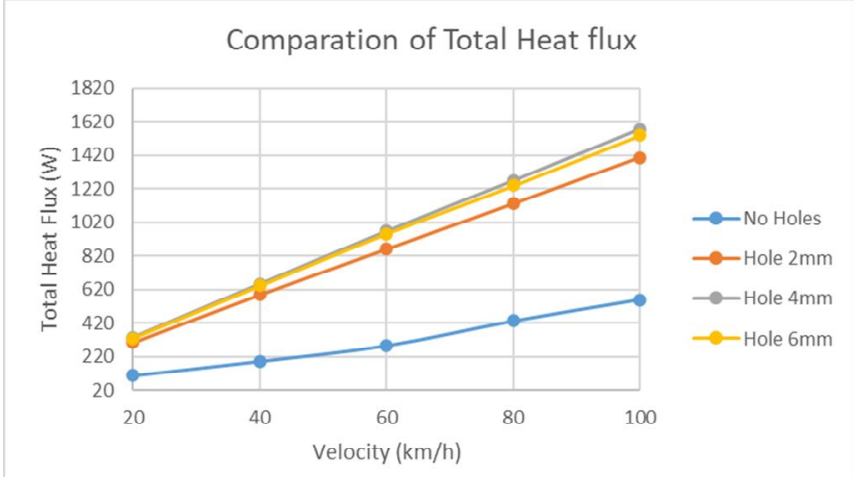

Figure 5: Graph of velocity's relationship to total heat flux on motorcycle fin

Figure 5 shows the total heat flux for each fin model. it appears that the perforated fin has a higher value than the fin without holes. The highest total heat flux was 1538.15 Watts for a perforated fin with $4 \mathrm{~mm}$ with a wind speed of $100 \mathrm{~km} / \mathrm{h}$. The addition of holes increases turbulence in the airflow inside the motorcycle fins.

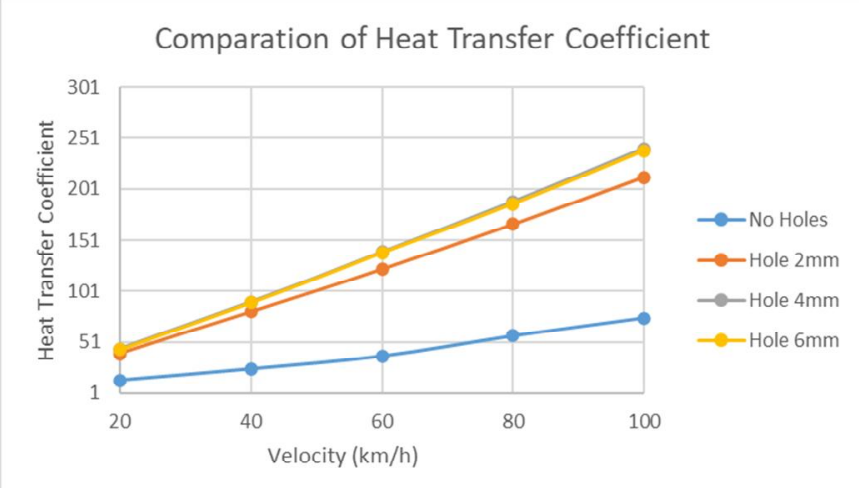

Figure 6: Graph of velocity's relationship to heat transfer coefficient on motorcycle fin

Figure 6 shows the result of $4 \mathrm{~mm}$ perforated convex geometry analysis is better than $2 \mathrm{~mm}$ and $6 \mathrm{~mm}$ perforated fins and non-perforated. Due to this, the rate of heat transfer has increased so that the coefficient of convection heat transfer increases and the decrease in the temperature of perforated fins is consistently higher than non-perforated fins, improving the efficiency and effectiveness of motorcycle fins so that the performance of motorcycle engines also increases. 


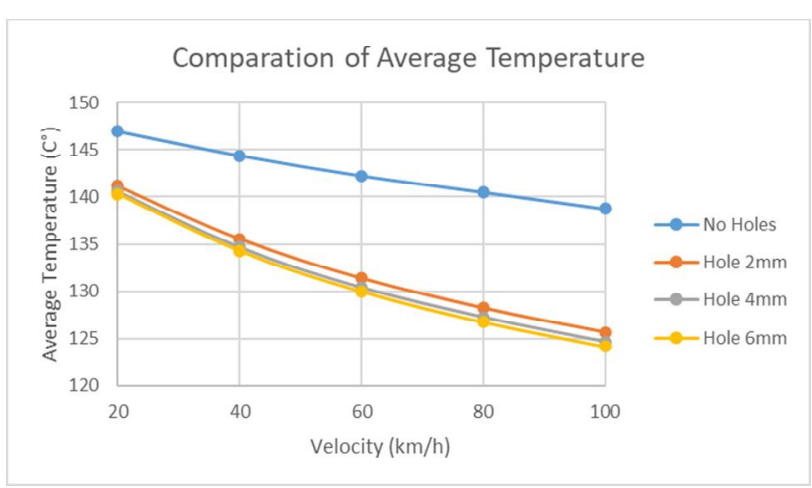

Figure 7: Graph of velocity's relationship to average temperature on motorcycle fin

Figure 7 shows the graph above shows that increasing wind speed will increase the rate of heat transfer to the effectiveness and efficiency of the machine is indicated by the distribution of temperature. consistently higher perforated fin temperature compared to non-perforated fins, improving the efficiency and effectiveness of motorcycle fins so that the performance of motorcycle engines also improved.

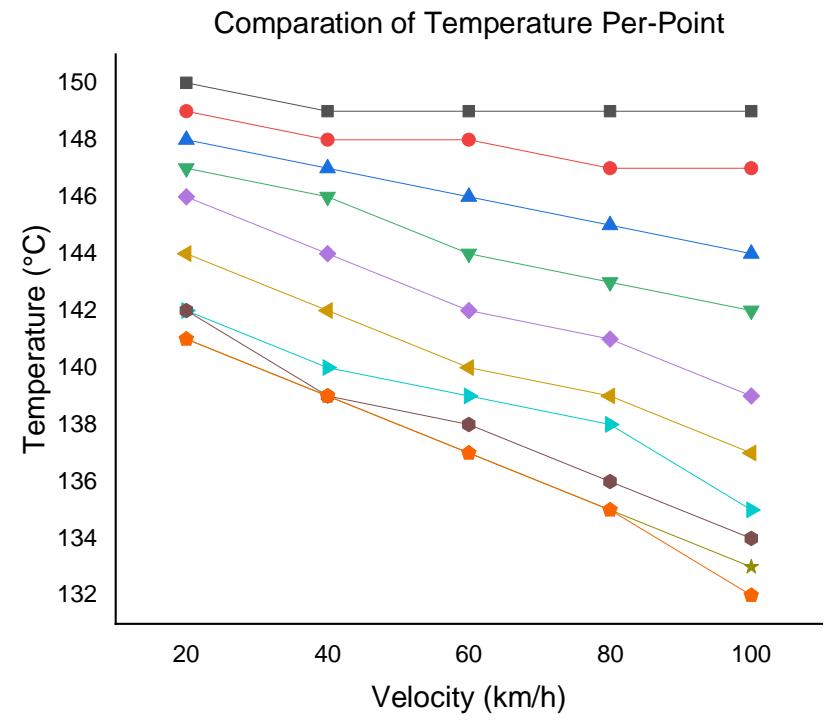

Figure 8: Graph of Velocity's relationship to Temperature on motorcycle fin

Figure 8 above shows that the increase in the speed of the vehicle affects the decrease in the temperature of the motorcycle fin. This can occur due to differences in temperature and wind speed bringing heat from upstream to downstream, so the decrease in significificant temperature occurs $\pm 20 \%$. The decrease in temperature that occurs with the increase in the air velocity will increase the rate of heat transfer and also increase the performance of the fins of motorcycle engines.

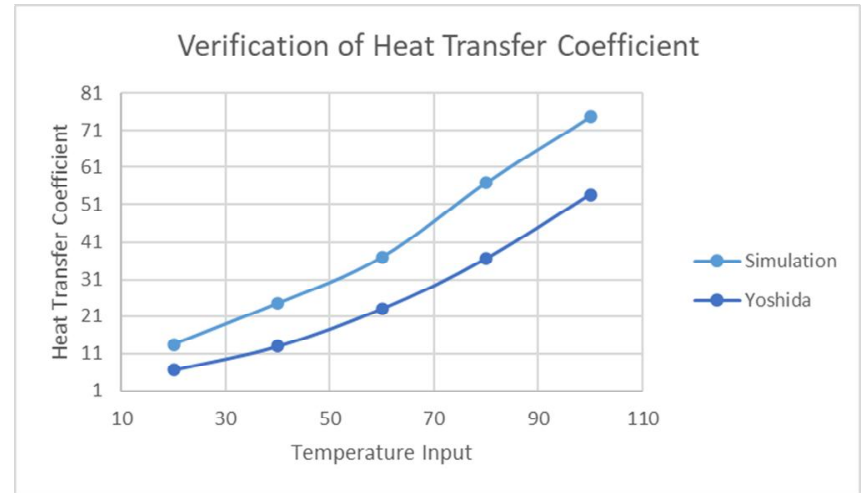

Figure 9: Graph of verification of heat transfer coefficient on motorcycle fin

Figure 9 shows the results of the simulation of diversification with experimental equations based on literature for the surface heat of the fin coefficient of heat transfer were determined using Yoshida's [15] experimental equation below :

$\alpha_{\text {avg }}=\left(2.47-2.55 / \mathrm{p}^{0.4}\right) \times u^{0.9} \times 0.0872 \mathrm{p}+4.31$

Where,

$\mathrm{A}_{\text {avg }}=$ Average heat transfer coefficient $\left[\mathrm{W} / \mathrm{m}^{2 \circ} \mathrm{C}\right]$

$\mathrm{p} \quad=$ Fin pitch $[\mathrm{mm}]$

$\mathrm{u} \quad=$ Velocity air $[\mathrm{km} / \mathrm{h}]$

Chart trends show that the simulation results performed are close to the results of the experiment with a maximum deviation of $\pm 10 \%$.

\section{CONCLUSION}

From the results of the study and the results of simulations using Computational Fluids Dynamics (CFD) software that has been conducted, there are several conclusions from the results of the distribution of temperature variations of different contours on motorcycle fin as follows :

In this study, designed motorcycle engine fins of the Honda Absolute Revo 110cc engine block type with convex-shaped annular fin geometry and simple 3D physical model motorcycle fin made using Autodesk Inventor Professional 2021 software. Aluminum 6061 used materials that have a thermal conductivity of $180 \mathrm{~W} / \mathrm{m} \bullet \mathrm{k}$ are selected because they are corrosion resistant, reducing vehicle weight and low fuel consumption resulting in improved engine performance.

The results of temperature distribution showed the dependence of heat transfer rate influenced by different wind speeds. Increased wind speed will increase the rate of heat transfer and also improve performance on motorcycle engine fins.

The result of $4 \mathrm{~mm}$ perforated convex geometry analysis is better than $2 \mathrm{~mm}$ and $6 \mathrm{~mm}$ perforated fins and non-perforated. Due to this, the rate of heat transfer increases 
so that the coefficient of convection heat transfer increases and the temperature of perforated fins is consistently higher than that of non-perforated fins, improving the performance of motorcycle engines.

\section{ACKNOWLEDGEMENT}

The author would like to thank the Director of Pontianak State Polytechnic for providing tuition assistance to complete the Master of Mechanical Engineering at Brawijaya University Malang.

\section{REFERENCES}

[1] PP No. 79, "PP Republik Indonesia Number 79 Year 2013 On Traffic Network and Road Transport," Jar. Traffic And Transport. Way, no. Government regulations of the Republic of Indonesia, pp. 1-97, 2013.

[2] G. Babu, "Heat Transfer Analysis and Optimization of Engine Cylinder Fins of Varying Geometry and Material," IOSR J. Mech. Civ. Eng., vol. 7, no. 4, pp. 24-29, 2013, doi: 10.9790/1684-0742429.

[3] D. Dubey, D. Singh, A. Yadav, S. Pal, and H. Thakur, "Thermal Analysis of Engine Cylinder having thick tip fin with varying slot sizes and material," Mater. Today Proc., vol. 4, no. 8, pp. 7636-7642, 2016, doi: 10.1016/j.matpr.2017.07.097.

[4] C. Thiagarajan, M. Prabhahar, S. Prakash, J. Senthil, and M. S. Kumar, "Heat transfer analysis and optimization of engine cylinder liner using different materials," Mater. Today Proc., no. xxxx, pp. 6-11, 2020, doi: 10.1016/j.matpr.2020.06.173.

[5] P. Sagar, P. Teotia, A. D. Sahlot, and H. C. Thakur, "Heat transfer analysis and optimization of engine fins of varying surface roughness," Mater. Today Proc., vol. 4, no. 8, pp. 8565-8570, 2017, doi: 10.1016/j.matpr.2017.07.203.

[6] P. Sagar, P. Teotia, A. D. Sahlot, and H. C. Thakur, "Heat transfer analysis and optimization of engine fins of varying geometry," Mater. Today Proc., vol. 4, no. 8, pp. 8558-8564, 2017, doi: 10.1016/j.matpr.2017.07.202.

[7] M. R. D. Suryawanshi, "Investigation of Different Fins across Engine by using Experimental and CFD Simulation," Int. J. Res. Appl. Sci. Eng. Technol., vol. 8, no. 8, pp. 275-283, 2020, doi: 10.22214/ijraset.2020.30876.

[8] W. H. A. R. A.- Doori, "Enhancement of Natural Convection Heat Transfer from the Rectangular Fins by Circular Perforations," Int. J. Automot. Mech. Eng., vol. 4, no. 12, pp. 428-436, 2011.

[9] K. Shahril, N. B. M. Kasim, and M. Sabri, "Heat transfer simulation of motorcycle fins under varying velocity using CFD method," IOP Conf. Ser. Mater. Sci. Eng., vol. 50, no. 1, 2013, doi:
10.1088/1757-899X/50/1/012043.

[10] R. C. Adhikari, D. H. Wood, and M. Pahlevani, "An experimental and numerical study of forced convection heat transfer from rectangular fins at low Reynolds numbers," Int. J. Heat Mass Transf., vol. 163, p. 120418, 2020, doi: 10.1016/j.ijheatmasstransfer.2020.120418.

[11] P. Agarwal, M. Shrikhande, and P. Srinivasan, "Heat transfer simulation by CFD from fins of an air cooled motorcycle engine under varying climatic conditions," Proc. World Congr. Eng. 2011, WCE 2011, vol. 3, pp. 2385-2389, 2011.

[12] M. and Versteeg, "An Introduction to Parallel Computational Fluid Dynamics," vol. 6, no. 4. 2005.

[13] Cangel, Yunus A., "Heat Transfer : A Practical Approach Second Edition," McGraw-Hill. New York, vol. 12. 2003.

[14] G. Juncu, "Brinkman-Forchheimer-Darcy Flow past an impermeable sphere embedded in a porous medium," Analele Stiint. ale Univ. Ovidius Constanta, Ser. Mat., vol. 23, no. 3, pp. 97-112, 2015, doi: 10.1515/auom-2015-0050.

[15] M. Yoshida, S. Ishihara, Y. Murakami, K. Nakashima, and M. Yamamoto, "Air-cooling effects of fins on a motorcycle engine," JSME Int. Journal, Ser. B Fluids Therm. Eng., vol. 49, no. 3, pp. 869-875, 2006, doi: 10.1299/jsmeb.49.869. 